Article

\title{
Research on Agricultural Carbon Emissions and Regional Carbon Emissions Reduction Strategies in China
}

\author{
Guofeng Wang ${ }^{1}$, Maolin Liao ${ }^{2, *}$ and Jie Jiang ${ }^{3, *}$ \\ 1 Faculty of International Trade, Shanxi University of Finance and Economic, Taiyuan 030006, China; \\ wanggf@sxufe.edu.cn \\ 2 Institute of Urban and Environmental Studies, Chinese Academy of Social Sciences, Beijing 100732, China \\ 3 School of Economics and Management, Beijing Youth Politics College, Beijing 100102, China \\ * Correspondence: liao_cass@sina.cn (M.L.); jiejiang010@126.com (J.J.)
}

Received: 22 February 2020; Accepted: 22 March 2020; Published: 26 March 2020

\begin{abstract}
Carbon emissions and strategies for reducing them have become hot topics in recent years. This study firstly measured the total amount and the intensity of agricultural carbon emissions (i.e., agricultural carbon emission per capital) in China. The results show that China's total carbon emission in 2016 was 272.022 million tons, which is $26.67 \%$ more than that in 2000 , with an average annual increase of $1.67 \%$. It then compared the regional differences of agricultural carbon emissions in China using the method of coefficient of variation and the Theil index. Following this, this paper finally provides scientific and technological support for the reduction of agricultural carbon emissions in China based on a matrix of carbon emission reduction strategies.
\end{abstract}

Keywords: agricultural carbon emissions; intensity of carbon emissions; analysis of regional differences; strategy for carbon emission reduction

\section{Introduction}

Carbon emission has become a key cause of climate change [1]. According to the Special Report on Global Warming of $1.5^{\circ} \mathrm{C}$ (SR15) released by the Intergovernmental Panel on Climate Change (IPCC), strict carbon emission control and emission reduction actions should be taken to keep the warming within $1.5^{\circ} \mathrm{C}[2,3]$. The 2019 Climate Change Conference (COP25) put forward that the world must set its goal to limit warming to $2.0^{\circ} \mathrm{C}$ [4]. According to the report of the IPCC on land use, carbon emissions caused by land use accounted for about $23 \%$ of total carbon emissions [5], of which the change of agricultural land use has been an important part [6]. From 2000-2016, agricultural arable land in China increased by 5.2\% [7]. The role of land as a carbon sink has been greatly affected by deforestation and agricultural land use [8], as farming is eroding soil at a rate between 10 times and more than 100 times faster than new soil forms [9]. Moreover, climate change has also increased the risks of extreme high temperatures and a shortage of rainfall [10].

Agricultural carbon emissions refer to the direct or indirect greenhouse gas emissions caused by the use of fertilizers, pesticides, and fossil fuels as well as waste treatment in agricultural production [11]. With the development of modern agriculture, the use of chemical fertilizers, pesticides, and especially agricultural machinery has led to an increase in agricultural carbon emissions [12]. The diversity and complexity of agricultural production has led to the diversity of agricultural carbon emission sources [13]. On one hand, carbon emissions can be caused by the use of pesticides, fertilizers, and energy as well as waste treatment [14]. On the other hand, rice cultivation and livestock breeding can also increase carbon emissions [15]. A large amount of $\mathrm{CH}_{4}, \mathrm{~N}_{2} \mathrm{O}$, and $\mathrm{CO}_{2}$ can be released during agricultural production. It has been estimated that $60 \%-80 \%$ of $\mathrm{N}_{2} \mathrm{O}$ emissions are directly and indirectly caused by 
farmland (indirect emissions refer to the production and transportation of fertilizers), field incineration, grazing, and animal manure [16]; $50 \%-70 \%$ of $\mathrm{CH}_{4}$ emissions are caused by the intestinal fermentation of livestock, rice cultivation, and animal manure; and $1 \%$ of $\mathrm{CO}_{2}$ emissions are caused by the production and use of agricultural machinery, fertilizers, and other chemical input [17]. According to the Food and Agriculture Organization (FAO), the five major agricultural carbon emission sources are soil $\left(38 \%, \mathrm{CH}_{4}+\mathrm{N}_{2} \mathrm{O}\right)$, the intestinal fermentation of ruminant animals $\left(32 \%, \mathrm{CH}_{4}\right)$, biomass fuel burning $\left(12 \%, \mathrm{CH}_{4}+\mathrm{N}_{2} \mathrm{O}\right)$, rice cultivation $\left(11 \%, \mathrm{CH}_{4}\right)$, and animal manure $\left(7 \%, \mathrm{CH}_{4}+\mathrm{N}_{2} \mathrm{O}\right)$ [18]. The main reasons for the increase of agricultural carbon emissions include the increase of population, changes in dietary structure (increasing consumption of animal by-products) [19], and technological progress (increasing fertilizer input, promotion of irrigation, and intensive agriculture). Reasons for the reduction of agricultural carbon emissions include the improvement of land productivity, the use of conservation tillage, and the implementation of environmental and non-environmental policies [20]. The amount of $\mathrm{CH}_{4}$ emissions caused by the intestinal fermentation of ruminant animals are related to the characteristics of the animals and the quality of fodder [19]. The amount of $\mathrm{CH}_{4}$ emissions caused by rice cultivation can be calculated by subtracting the amount of oxidation of $\mathrm{CH}_{4}$ by the $\mathrm{CH}_{4}$-oxidizing bacteria at the root of rice from the amount of $\mathrm{CH}_{4}$ formed by methanogens in rice fields in the anaerobic environment through the conversion of organic matter in the rhizosphere of field plants. The methane emissions of rice cultivation are mainly affected by soil properties, irrigation and water conditions, use of fertilizers, rice growth, and climate conditions. The storage and treatment of livestock manure can also lead to $\mathrm{CH}_{4}$ emissions [21]. The amount of $\mathrm{CH}_{4}$ emissions caused by livestock manure are related to the methods of manure treatment and climate conditions. The $\mathrm{N}_{2} \mathrm{O}$ emissions from soil are driven by the mechanism of nitrification and denitrification with the participation of soil microorganisms. It is generally believed that the mechanism of denitrification makes greater contributions to $\mathrm{N}_{2} \mathrm{O}$ emissions than that of nitrification [22]. $\mathrm{N}_{2} \mathrm{O}$ emissions can be affected by many factors, such as the type of crops, the quality of soil, fertilizers, irrigation technologies, and climate conditions [23].

Agricultural greenhouse gas emissions are generally estimated according to Volume 4 of the 2006 IPCC Guidelines for National Greenhouse Gas Inventories [24]. Considering that greenhouse gas emissions can be affected by many factors, some experts in ecology and agronomy have adjusted the related parameters, formulas, and influencing factors based on long-term field experiments and monitoring. For example, the Rodale Institute, led by David Pimental, a well-known professor of ecology at Cornell University, conducted the Farming System Trial on three plots-a traditional intensive agriculture (fertilizers) plot, an organic agriculture (manure) plot, and a legume rotation organic agriculture (plant nitrogen fixation) plot-to analyze the differences in energy input, soil organic matter, water quality, biological resources, production level, and labor input from 1981 to 2002. This experiment provided important data for estimating the potential of agricultural carbon emission reduction and analyzing the cost of emission reduction from an economic perspective [25].

Agricultural carbon emissions can be measured in many different ways. In 2002, scholars proposed measuring the agricultural carbon emissions from crop farming through the energy consumed by fertilizers, pesticides, irrigation, and seed cultivation [21]. Later, scholars began to measure the agricultural carbon emissions from the random discharge and storage of agricultural waste, livestock and poultry intestines, agricultural production processes, rice cultivation, and straw burning $[16,18,20,23]$. It has been estimated that the total agricultural carbon emissions in 2008 were about 427.5 tons, and within this the use of agricultural land as the main cause accounted for about $50 \%$ of the carbon emissions [14]. Moreover, carbon emissions from the intestinal fermentation of livestock and poultry accounted for about a third of the total emissions [20]. The soil carbon emissions model, which takes the climate conditions and the quality of soil into consideration, has been widely applied in the field of natural sciences. The transformation of agricultural land use can also lead to great agricultural carbon emissions. Besides, through the comparison of experiences in the USA, Canada, and New Zealand it has been found that differences in the agricultural carbon emissions of countries could be explained by agricultural production methods [14,17]. 
The estimation of agricultural carbon emissions in China has been focused on carbon emission sources. For example, some scholars have estimated the agricultural carbon emissions based on the measurement of conversion factors of coal, oil, natural gas, and other resources used in agricultural production [20-23]. Some others have measured the carbon emissions caused by changes in the agricultural land use in some ethnic regions in China through the measurement of carbon emissions from fertilizers, pesticides, agricultural plastic films, diesel fuels, conservation tillage, and irrigation technology $[10,12,14,15]$. Besides, the perspective of input-output, which takes electricity consumption into consideration, has been used by some scholars to measure the agricultural carbon emissions in Chongqing [23]. Recently, further research has been undertaken on the carbon emissions of livestock and poultry, including cows, sheep, goats, pigs, chickens, and ducks [24,25].

In general, the measurement of agricultural carbon emissions has been modified a lot since it was proposed. A general research framework with differences in the selection of secondary indicators has been developed to make estimations of the carbon emissions caused by agricultural land use (or material input in agriculture) and livestock and poultry farming $[18,20,22]$. However, the estimation of carbon emissions from rice cultivation and soil has not been standardized [23]. Carbon emissions from rice cultivation are usually estimated by multiplying the area of rice cultivation by a given coefficient, which varies between institutions. Some institutions use coefficients with regional differences while others use the same coefficient for the whole country [21]. As for the carbon emissions from soil, they are usually estimated based on the relevant experimental data from a certain area rather than data collected nationwide. However, carbon emissions from soil can be affected greatly by cultivation methods. Therefore, the agricultural carbon emissions in this paper have been estimated without considering the carbon emissions from soil. Rice cultivation has been estimated with a coefficient that reflects both regional differences and differences in species.

Based on an input-output table, some economists have estimated the carbon emissions from direct and indirect energy consumption at each upstream production stage of agricultural inputs with the method of environmental input-output (EIO) and the method of the life cycle of agricultural production (LCA) [26]. Furthermore, scholars and institutions, such as the World Resources Institute, the World Business Council for Sustainable Development, Matthews, and II. S., have proposed the Tiered Input-Output Life Cycle Assessment (TIO-LCA) [27] to prioritize agricultural emission reduction actions. It should be noted that the existing studies on the estimation of agricultural carbon emissions were mainly conducted by comparing traditional intensive agriculture and organic agriculture. Some foreign scholars have conducted a comparative study on the environmental impact of traditional intensive agriculture and organic agriculture in Australia with the hybrid input-output life cycle method. Samples selected in the research covered different regions, species of crops, scales, and methods of cultivation as well as different growing seasons [16]. In terms of the research method, the direct carbon emissions from on-farm production activities and other environmental impacts were estimated with the method of the life cycle, indirect carbon emissions from off-farm production activities was estimated with the method of input-output, and the agricultural emission reduction actions were prioritized through analysis of the structural path [16]. This research provided a comprehensive estimation of carbon emissions throughout the agricultural production process, measured the energy consumption (including the consumption of electricity, fertilizers, pesticides, seeds, and fodder) of fruits, vegetables, and livestock products and compared the energy consumption structure of agricultural production in different regions of Australia. The results show that, although the amount of water utilization and labor input in organic agriculture is higher than that in traditional intensive agriculture, the indirect contributions of other aspects (such as energy utilization and greenhouse gas emissions) in organic agriculture are much better than those in traditional intensive agriculture. Therefore, the indirect impacts (especially in off-farm production activities) have to be taken into consideration when estimating the environmental sustainability of different farming methods.

According to the estimation of agricultural carbon emissions in the United States, about half of the carbon emissions caused by agricultural production come from the use of agricultural land, while about a 
third come from the intestinal fermentation of livestock. The proportion of agricultural carbon emissions in total carbon emissions is highly related to the agricultural practices of different countries [28]. According to the estimation of carbon emissions from different emission sources (fertilizers, energy consumption, and crop cultivation) conducted by scholars in China [29], carbon emissions from fertilizers accounted for the largest proportion of carbon emissions [30]. Carbon emissions in China have been increasing since 1995 [31], but the growth rate has declined in recent years [32]. It has been found that all the carbon emissions from farmland, carbon sequestration, and the carbon footprint in 31 provinces in China have increased. Besides, according to research conducted in Heilongjiang, the field ecosystem is the main source of carbon emissions. The research also showed a positive correlation between agricultural carbon emissions and the input of agricultural chemicals, energy consumption, and farming forms [33]. Traditional cultivation ways cause a large amount of carbon emissions. Agricultural carbon emissions can be affected by the method of land use. It has been proven that agricultural carbon emissions can be effectively reduced by afforestation and the Grain for Green Program [34]. Carbon emissions from construction land are the highest, compared with those from urban land, rural residential land, land for transportation, and agricultural land [35].

It can be seen that further research is needed into regional agricultural carbon emissions. Therefore, using the coefficient of variation and the Theil index, this paper analyzes the spatial and temporal heterogeneity of agricultural carbon emissions in different regions of China and makes policy recommendations to support the reduction of agricultural carbon emissions. The second part is method and data, the third part is the regional differences of agricultural carbon emissions, the forth part is agricultural carbon emissions per capita and intensity, the fifth part is policy recommendations for the reduction of regional agricultural carbon emissions, and the last part is conclusions and discussion.

\section{Method and data}

\subsection{Measure of Agricultural Carbon Emissions by Province}

The data in this paper were collected from the China Rural Statistical Yearbook, the China Statistical Yearbook, and the Economy Prediction System (EPS) Database (Beijing fuqua information technology co. LTD: Beijing, China). The prices used in this paper were converted according to the price in 2000.

\subsubsection{Carbon Emissions from Agricultural Land Use}

This paper mainly estimated the agricultural carbon emissions from fertilizers, pesticides, agricultural plastic films, diesel fuel consumption, crop sowing, and irrigation. The emission factors are shown in Table 1.

Table 1. Emission factors of different carbon emission sources in land use.

\begin{tabular}{ccc}
\hline Sources & Emission Factors & References \\
\hline Fertilizer & $0.8956 \mathrm{~kg}(\mathrm{C}) / \mathrm{kg}$ & {$[36-38]$} \\
Pesticide & $4.9341 \mathrm{~kg}(\mathrm{C}) / \mathrm{kg}$ & {$[36,39,40]$} \\
Agricultural plastic films & $5.18 \mathrm{~kg}(\mathrm{C}) / \mathrm{kg}$ & {$[41-44]$} \\
Diesel fuel & $0.5927 \mathrm{~kg}(\mathrm{C}) / \mathrm{kg}$ & {$[5]$} \\
Sowing & $266.48 \mathrm{~kg}(\mathrm{C}) / \mathrm{hm}^{2}$ & {$[45-48]$} \\
Irrigation & \\
\hline
\end{tabular}

Based on these factors, the carbon emission was estimated as follows:

$$
\mathrm{E}=E_{f e}+E_{p e}+E_{p l}+E_{g a}+E_{s o}+E_{i r}
$$

where $\mathrm{E}$ is the total carbon emission caused by agricultural land use and $E_{f e}, E_{p e}, E_{p l}, E_{g a}, E_{s o}$, and $E_{i r}$ are estimated on the basis of the parameters of fertilizers, pesticides, agricultural plastic films, diesel fuel consumption, the sowing area, and the effective irrigation area. 


\subsubsection{Carbon Emissions from Rice Cultivation}

The carbon emission of rice cultivation in this paper was estimated according to the standard of the FAO. Rice cultivation can be greatly affected by climate conditions [25]. Rice is one of the most important emission sources of $\mathrm{CH}_{4}$. Additionally, the $\mathrm{CH}_{4}$ emission of rice in different growth cycles can be affected by climate and hydrothermal conditions. Therefore, based on the existing calculation model of carbon emission coefficient [39], the $\mathrm{CH}_{4}$ emission factors of rice in this paper was estimated according to the data on climate, soil, and hydrology in different provinces (see Table 2).

Table 2. Carbon emission factors of rice cultivation in different provinces.

\begin{tabular}{cccccc}
\hline Province & $\begin{array}{c}\text { Emission } \\
\text { Factors }\left(\mathbf{g} / \mathbf{m}^{\mathbf{2}}\right)\end{array}$ & Province & $\begin{array}{c}\text { Emission } \\
\text { Factors }\left(\mathbf{g} / \mathbf{m}^{\mathbf{2}}\right)\end{array}$ & Province & $\begin{array}{c}\text { Emission } \\
\text { Factors }\left(\mathbf{g} / \mathbf{m}^{\mathbf{2}}\right)\end{array}$ \\
\hline Beijing & 13.23 & Anhui & 31.91 & Sichuan & 16.91 \\
Tianjin & 11.34 & Fujian & 34.62 & Guizhou & 16.12 \\
Hebei & 15.33 & Jiangxi & 42.2 & Yunnan & 5.73 \\
Shanxi & 6.62 & Shandong & 21.02 & Tibet & 6.83 \\
Inner Mongolia & 8.93 & Henan & 17.85 & Shanxi & 12.51 \\
Liaoning & 9.24 & Hubei & 38.23 & Gansu & 6.83 \\
Jilin & 5.57 & Hunan & 35.01 & Qinghai & 0 \\
Heilongjiang & 8.31 & Guangdong & 41.22 & Ningxia & 7.35 \\
Shanghai & 31.26 & Guangxi & 36.44 & Xinjiang & 10.52 \\
Jiangsu & 32.4 & Hainan & 38.43 & & \\
Zhejiang & 35.6 & Chongqing & 16.91 & & \\
\hline
\end{tabular}

\subsubsection{Carbon Emission from Ruminant Animals}

Carbon emissions from livestock and poultry farming (especially ruminant farming) are another important source of agricultural carbon emissions. The emissions include $\mathrm{CH}_{4}$ emissions caused by the intestinal fermentation of livestock and poultry, and the $\mathrm{CH}_{4}$ and $\mathrm{N}_{2} \mathrm{O}$ emissions (according to the United Nations Intergovernmental Panel on Climate Change (IPCC) and the greenhouse gas accounting method in China's "Guidelines for the Preparation of Provincial Greenhouse Gas Inventories (Trial)", the $\mathrm{N}_{2} \mathrm{O}$ in the atmosphere mainly comes from agricultural land, animal manure management, and the wastewater treatment processes of the waste treatment sector, among which more than $70 \%$ of the nitrogen emissions come from agricultural production. As this paper is about agricultural carbon emissions, $\mathrm{N}_{2} \mathrm{O}$ emissions have not been measured and only the $\mathrm{CH}_{4}$ emissions have been taken into consideration) that occur during manure treatment. In this paper, we only measured the carbon emission factors of cattle, horses, donkeys, mules, pigs, goats, sheep, and poultry [32] (see Table 3).

Table 3. Carbon emission factors of different animals.

\begin{tabular}{cccccc}
\hline $\begin{array}{c}\text { Ruminant } \\
\text { Animal }\end{array}$ & $\begin{array}{c}\text { Emission Factors } \\
\text { of Intestinal } \\
\text { Fermentation } \\
(\mathbf{k g}(\mathbf{C}) / \mathbf{u n i t} / \text { year) }\end{array}$ & $\begin{array}{c}\text { Emission Factors } \\
\text { of Manure } \\
\text { Treatment } \\
\text { (kg(C)/unit/year) }\end{array}$ & $\begin{array}{c}\text { Ruminant } \\
\text { Animal }\end{array}$ & $\begin{array}{c}\text { Emission Factors } \\
\text { of Intestinal } \\
\text { Fermentation } \\
\text { (kg(C)/unit/yea) }\end{array}$ & $\begin{array}{c}\text { Emission Factors } \\
\text { of Manure } \\
\text { Treatment } \\
\text { (kg(C)/unit/year) }\end{array}$ \\
\hline Cattle & 395.56 & 24.55 & Pig & 6.82 & 27.28 \\
Horses & 122.76 & 11.18 & Goat & 34.11 & 1.16 \\
Donkeys & 68.21 & 6.14 & Sheep & 32.11 & 1.02 \\
Mules & 68.21 & 6.14 & Poultry & 0 & 0.02 \\
\hline
\end{tabular}

Carbon emissions from livestock and poultry in each province were estimated with the number of poultry produced in each province by the end of the year and the number of other animals kept in each province by the end of the year. Based on the methods proposed in current research [27], the number of poultry used in this paper was modified as follows: 


$$
N=\text { Days_alive } * \frac{M}{365}
$$

where $N$ is the modified number of poultry, Days_alive is the growth cycle of poultry (here this equals $55)$, and $\mathrm{M}$ is the number of poultry produced in each province by the end of the year.

In order to simplify the estimation, the emission of $\mathrm{CH}_{4}$ in this paper was converted to that of standard C. According to the report issued by the IPCC, the greenhouse effect caused by 1 ton of $\mathrm{CH}_{4}$ is equivalent to that caused by 6.82 tons of $\mathrm{C}\left(25\right.$ tons of $\left.\mathrm{CO}_{2}\right)$.

\subsection{Coefficient of Variation}

In this paper, the changes in agricultural carbon emission per capita were reflected by the coefficient of variations.

$$
C V=\frac{1}{\bar{X}}\left[\frac{1}{n} \sum_{i=1}^{n}\left(X_{i}-\bar{X}\right)^{2}\right]^{\frac{1}{2}}
$$

where, $\bar{X}$ is the agricultural carbon emission per capita at the national level, $X_{i}$ is the agricultural carbon emission per capita of the eight economic zones, and $n$ is the number of regions in the economic zone. The larger the value of $C V$ is, the greater the difference among regional agricultural carbon emissions per capita is.

\subsection{Theil Index}

The Theil index has been widely used in the measurement of income inequality since it was proposed. With the Theil index, the overall difference can be divided into two parts. One is brought about by regional differences, and the other is brought about by intra-regional differences. The Theil index was adopted here to explain the overall difference of agricultural carbon emissions in eight economic zones [49]. In this case, the contribution rates of regional differences and intra-regional differences to the overall agricultural carbon emissions were measured with the Theil index.

$$
\begin{gathered}
T_{i}=\sum_{i=1}^{n} \frac{G D P_{j}}{G D P_{i}} \cdot \ln \left(\frac{G D P_{j}}{G D P_{i}} \cdot \frac{A C E_{i}}{A C E_{j}}\right) \\
T_{w r}=\sum_{i=1}^{n} A C E_{i} \cdot\left(\sum_{j=1}^{m} A C E_{i j} \cdot \ln \frac{A C E_{i j}}{G D P_{i j}}\right) \\
T_{b r}=\sum_{i=1}^{n} A C E_{i} \cdot \ln \frac{A C E_{i}}{G D P_{i}} \\
T=T_{w r}+T_{b r} \\
T_{w r} \%=\frac{T_{w r}}{T} \% \\
T_{b r} \%=\frac{T_{b r}}{T} \%
\end{gathered}
$$

where $A C E$ represents the total agricultural carbon emission, GDP is the total output of the agricultural and forestry economy, GDP ${ }_{j}$ is the proportion of the $j$-th province's GDP within the national GDP, and $G D P_{i}$ is the proportion of the $i$-th economic zone's GDP within the national GDP. $A C E_{j}$ is the proportion of the $j$-th province's agricultural carbon emissions within the national agricultural carbon emissions and $A C E_{i}$ is the proportion of the $i$-th economic zone's agricultural carbon emissions in the national agricultural carbon emissions. $T$ is the overall difference in agricultural carbon emissions, $T_{w r}$ is the regional difference in agricultural carbon emissions, $T_{b r}$ is the difference in agricultural 
carbon emissions within the regions, $T_{w r} \%$ is the contribution rate of regional differences to the overall difference, and $T_{b r} \%$ is the contribution rate of differences within regions to the overall difference.

\subsection{Research Area Division}

Agricultural carbon emissions are different in different regions. Based on existing research [46], the research areas were divided into four parts (the eastern region, central region, western region, and northeast region) and eight economic zones (the northern coast, eastern coast, southern coast, the middle reaches of the Yangtze River, the middle reaches of the Yellow River, the northwest region, the southwest region, and the northeast region), respectively (see Figure 1), according to similarities in agricultural production activities and the possibility of regional cooperation to reduce emissions.

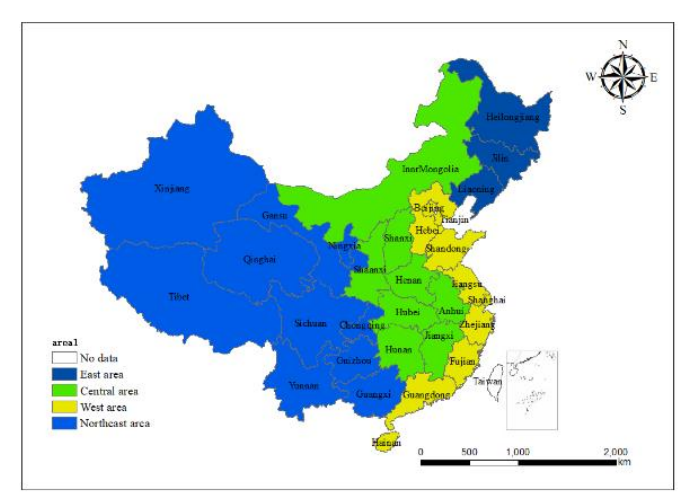

(a)

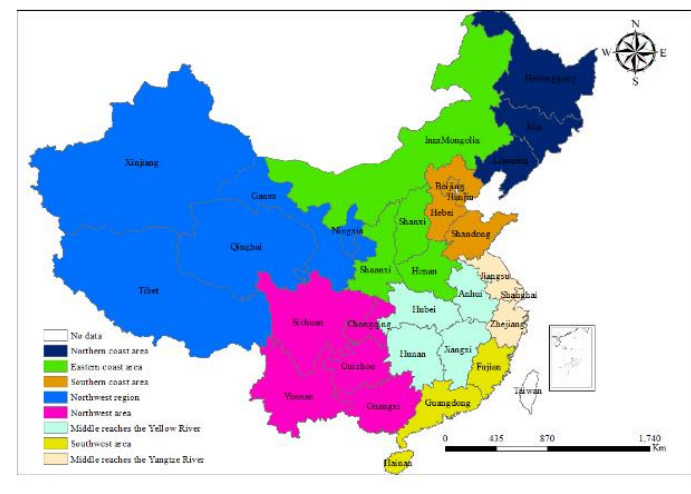

(b)

Figure 1. Division of agricultural carbon emission regions in China. ((a): four parts; (b): eight economic zones).

\section{Regional Differences of Agricultural Carbon Emissions}

\subsection{Overall Analysis of Agricultural Carbon Emissions}

The outcomes of the measurements of agricultural carbon emissions from 2000 to 2016 are shown in Table 4.

Table 4. Amount and composition of agricultural carbon emissions from 2000 to 2016 (10,000 tons, \%).

\begin{tabular}{cccccccc}
\hline Year & $\begin{array}{c}\text { Livestock and } \\
\text { Poultry }\end{array}$ & Proportion & $\begin{array}{c}\text { Rice } \\
\text { Planting }\end{array}$ & Proportion & Land Use & Proportion & $\begin{array}{c}\text { Total Carbon } \\
\text { Emission }\end{array}$ \\
\hline 2000 & 7110.37 & $33.11 \%$ & 6970.28 & $32.46 \%$ & 7394.73 & $34.43 \%$ & $21,475.39$ \\
2001 & 7388.96 & $34.08 \%$ & 6702.59 & $30.91 \%$ & 7591.67 & $35.01 \%$ & $21,683.21$ \\
2002 & 7840.99 & $35.42 \%$ & 6561.16 & $29.64 \%$ & 7737.22 & $34.95 \%$ & $22,139.37$ \\
2003 & 8246.21 & $36.97 \%$ & 6161.2 & $27.62 \%$ & 7898.37 & $35.41 \%$ & $22,305.77$ \\
2004 & 8743.59 & $36.94 \%$ & 6599.31 & $27.88 \%$ & 8327.02 & $35.18 \%$ & $23,669.93$ \\
2005 & 9668.35 & $38.74 \%$ & 6709.68 & $26.88 \%$ & 8579.98 & $34.38 \%$ & $24,958.01$ \\
2006 & 9655.05 & $38.27 \%$ & 6734.6 & $26.70 \%$ & 8835.89 & $35.03 \%$ & $25,225.53$ \\
2007 & 7786.83 & $32.90 \%$ & 6727.58 & $28.43 \%$ & 9152.28 & $38.67 \%$ & $23,666.68$ \\
2008 & 9770.14 & $37.80 \%$ & 6803.02 & $26.32 \%$ & 9271.86 & $35.87 \%$ & $25,845.02$ \\
2009 & 8376.28 & $33.75 \%$ & 6892.05 & $27.77 \%$ & 9550.08 & $38.48 \%$ & $24,818.4$ \\
2010 & 8624.36 & $33.93 \%$ & 6950.42 & $27.34 \%$ & 9844.54 & $38.73 \%$ & $25,419.31$ \\
2011 & 8567.85 & $33.40 \%$ & 6993.17 & $27.26 \%$ & $10,087.97$ & $39.33 \%$ & 25,649 \\
2012 & 8872.77 & $33.85 \%$ & 7011.92 & $26.75 \%$ & $10,326.52$ & $39.40 \%$ & $26,211.2$ \\
2013 & 9067.12 & $34.08 \%$ & 7051.94 & $26.50 \%$ & $10,488.77$ & $39.42 \%$ & $26,607.84$ \\
2014 & 9317.74 & $34.52 \%$ & 7050.57 & $26.12 \%$ & $10,620.52$ & $39.35 \%$ & $26,988.84$ \\
2015 & 9251.71 & $34.32 \%$ & 7027.79 & $26.07 \%$ & $10,679.59$ & $39.61 \%$ & $26,959.09$ \\
2016 & 9126.42 & $33.55 \%$ & 7019.3 & $25.80 \%$ & $11,056.49$ & $40.65 \%$ & $27,202.2$ \\
\hline
\end{tabular}


In 2016, China's total carbon emissions were 272.022 million tons, which is $26.67 \%$ more than that in 2000, with an average annual increase of $1.67 \%$. The carbon emissions caused by land use, rice planting, and livestock and poultry were $110.5649,70.193$, and 91.2642 million tons, respectively, accounting for $40.64 \%, 25.8 \%$, and $33.55 \%$ of the agricultural carbon emissions, respectively.

Agricultural carbon emissions increased greatly from 2000 to 2016 in total. However, there were several fluctuations. To be specific, agricultural carbon emissions increased slowly from 2000-2003 while they increased rapidly from 2004-2006. Later, between 2006 and2008, agricultural carbon emissions declined slightly and then increased. Since then, agricultural carbon emissions have remained stable. This can be explained by the fluctuation of the rice cultivation acreage. Based on this, it was estimated that agricultural carbon emissions will continue to increase in the next few years.

As agricultural carbon emissions are susceptible to the total amount of resources in each province, the agricultural carbon emissions of 31 provinces in this paper were evaluated by the intensity of carbon emissions (ton/10,000 yuan), which refers to the agricultural carbon emissions caused by the gross agricultural output value per 10,000 yuan. It can be seen from Figure 2 that the intensity of carbon emissions declined from 0.86 ton/10,000 yuan in 2000 to 0.24 ton/10,000 yuan in 2016. Additionally, the largest decline appeared in 2003-2004, which was brought about by the issue of the No. 1 central document with an aim to increase the income of farmers. Compared with the agricultural output value of 2003, that of 2004 was doubled and the intensity of carbon emissions has declined steadily since 2004. It can be predicted that the intensity of agricultural carbon emissions in China will continue to decline in the next few years.

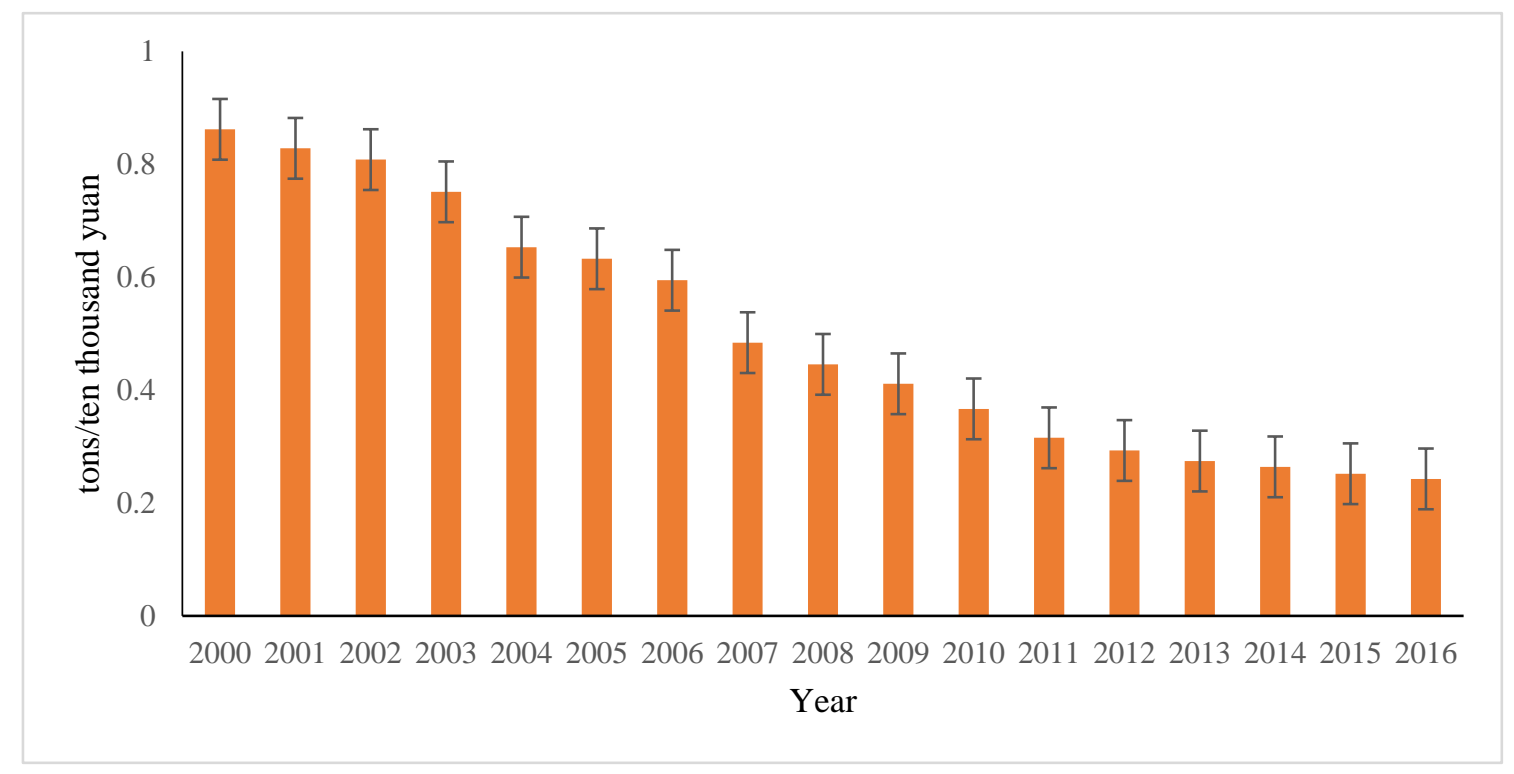

Figure 2. Intensity of agricultural carbon emissions from 2000-2016.

Agricultural carbon emissions can be divided into three categories: carbon emissions from agricultural land use, carbon emissions from rice cultivation, and carbon emissions from livestock and poultry farming. The total agricultural carbon emissions increased from 2000-2016. To be specific, carbon emissions from agricultural land use increased the fastest, from 73.9473 to 110.5649 million tons, with an average annual increase of $3.09 \%$. This means the increase of agricultural output in China depended greatly on the increase of agricultural material input. There were great fluctuations in the carbon emissions from rice cultivation, which increased slightly from 69.7028 million tons in 2000 to 70.193 million tons in 2016 with an average annual increase of $0.04 \%$. The carbon emissions from rice cultivation were mainly affected by the scale and structure of rice cultivation. Carbon emissions from livestock and poultry farming increased from 71.1037 million tons in 2000 to 91.2642 million tons in 2016 with an average annual increase of $1.77 \%$. Affected by the scale and structure of livestock and 
poultry farming, the change of carbon emissions from livestock and poultry farming can be divided into five periods: a period of continuous rising (2000-2005), a period of rapid declining (2006-2007), a period of rapid rising (2007-2008), a period of declining (2008-2009), and a period of steady growth (2009-2016).

\subsection{Regional Variation of Agricultural Carbon Emissions}

In terms of total agricultural carbon emissions, the central region has always ranked first, while the eastern region ranked second until 2013 when it was surpassed by the western region. Agricultural carbon emissions in the central region, western region, and the northeast region increased slowly from 2000 to 2016, while agricultural carbon emissions in the eastern region were stable from 2000-2006 and declined from 2010-2015. This was positively related to the technological and green transformation during this period.

The eight economic zones in China were roughly divided into four groups according to their agricultural carbon emissions from 2000 to 2016. The first group included the middle reaches of the Yangtze River and the southwest region. The second group was the middle reaches of the Yellow River. The third group included the northern coast and the northeast region. The fourth group included the eastern coastal economic zone, the southern coastal economic zone, and the northwest economic zone. To be specific, the middle reaches of the Yangtze River were the highest. The agricultural carbon emissions in the middle reaches of the Yangtze River and the Yellow River increased significantly, while those in the eastern coastal economic zone and the southern coastal economic zone remained stable.

\section{Agricultural Carbon Emissions Per Capita and Intensity}

\subsection{Analysis of Carbon Emission Per Capita}

From 2000 to 2016, the agricultural carbon emissions in four regions increased with significant differences in their trends. To be specific, carbon emissions per capita in the northeast region rose rapidly, which could be explained by the large-scale cultivation of corn. In the eastern, central, and western regions, carbon emissions per capita were highest in 2006 and then increased slowly.

From 2000 to 2016, there were great differences among agricultural carbon emissions per capita in different regions. Specifically, in 2016, agricultural carbon emissions per capita in the northeast region were 0.9986 tons, which is the highest, followed by those in the northwest region, the middle reaches of the Yangtze River, the southwest region, the northern coast, the eastern coast, and the southern coast. Emissions per capita had a positive relation with the level of economic development.

From 2000 to 2016 (see Figure 3), the intensity of agricultural carbon emissions in the four regions showed a downward trend. Moreover, agricultural carbon emissions declined rapidly from 2007-2012 and then showed a slowing rate of decline from 2013. The agricultural carbon emissions intensity in the eastern region were the lowest over the years, indicating that the carbon emissions from agricultural production in the eastern region were the lowest. 


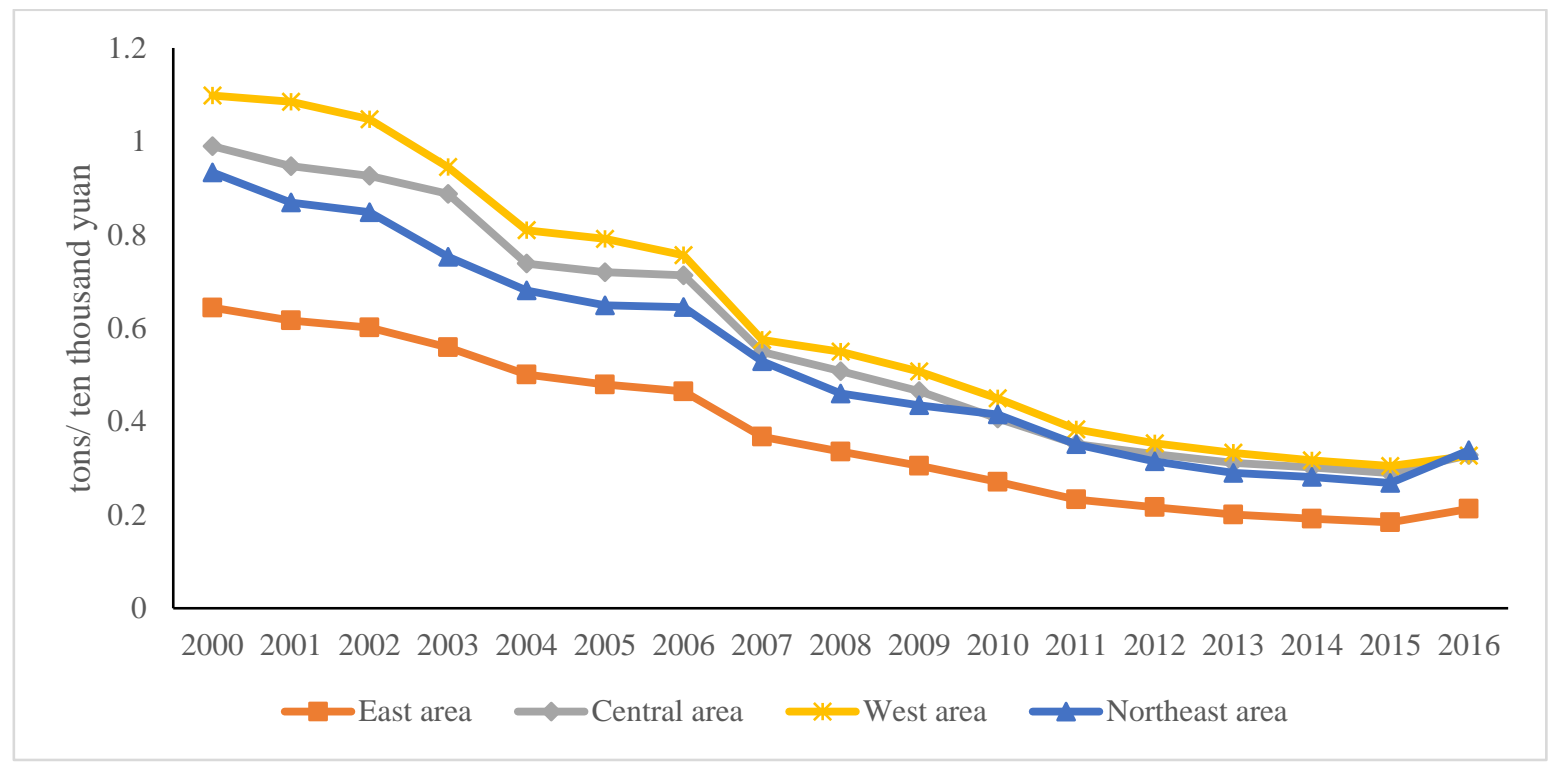

Figure 3. Intensity of agricultural carbon emissions in four regions.

\subsection{Analysis of Carbon Emission Intensity}

From 2000 to 2016, the carbon emission intensity in the northwest was relatively high (Figure 4), especially in 2000. However, the intensities of all economic zones dropped significantly by the year 2016, when the intensity of carbon emissions in the northwest was the highest, followed by the middle reaches of the Yangtze River, the northeast region, the middle reaches of the Yellow River, the southwest region, the northern coast, the eastern coast, and the southern coast, indicating that the intensity of carbon emissions in Guangzhou and other regions was the lowest.

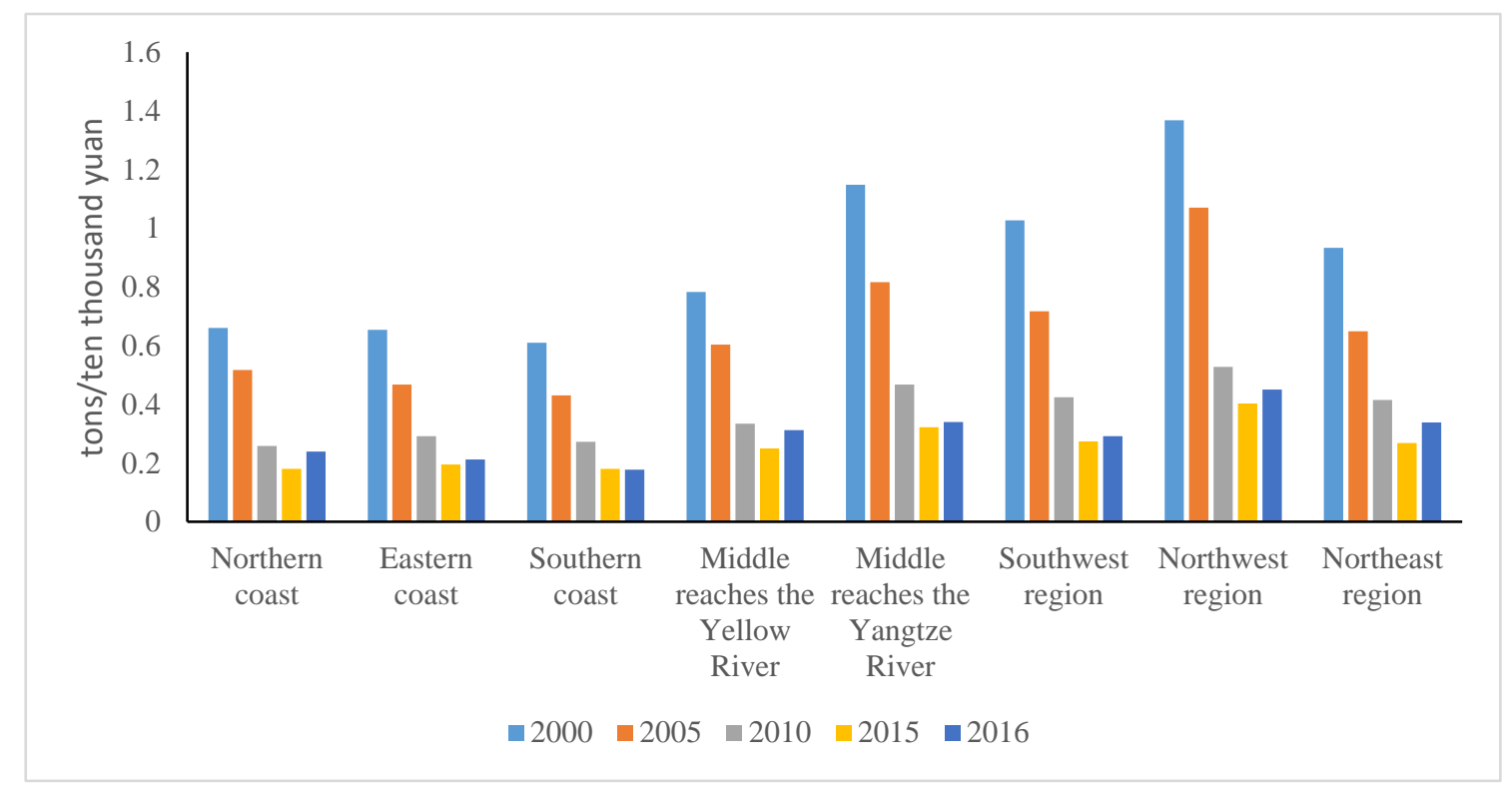

Figure 4. Intensities of agricultural carbon emissions in eight economic zones.

There were great fluctuations in the intensity of agricultural carbon emissions from 2000 to 2016. However, the intensity of agricultural carbon emissions in all province declined from 2000 to 2016. In 2016, the intensity of carbon emissions in Tibet ranked first, which was 3.93 tons/10,000 yuan, while the intensity of carbon emissions in Fujian was only 0.63 tons/10,000 yuan which was the lowest. 
Except for Tibet, Qinghai, and Xinjiang, the agricultural carbon emissions in other provinces caused by agricultural land use all increased. According to the main source of the carbon emissions, these provinces can be divided into five groups: land-use-dominated regions (the agricultural carbon emissions were mainly caused by agricultural activities), rice-cultivation-dominated regions (the agricultural carbon emissions were mainly caused by rice cultivation), livestock-and-poultry-farming-dominated regions (the agricultural carbon emissions were mainly caused by livestock and poultry farming), compound-factor-dominated regions (the agricultural carbon emissions were mainly caused by agricultural land use and rice cultivation, rice cultivation and livestock and poultry farming, agricultural land use and livestock and poultry farming, and the carbon emissions from other factors only accounted for a small proportion, usually below $20 \%$ ), and balanced regions.

From 2000 to 2016, carbon emissions caused by the use of agricultural land increased year by year. Crop planting was the main agricultural activity in these regions, while livestock and poultry farming and rice cultivation only accounted for a tiny percentage of their agricultural activities. With the implementation of China's rural revitalization strategy, especially the development of green agriculture and forestry industry, agricultural carbon emissions will gradually decline.

\subsection{Variation of Regional Agricultural Carbon Emissions}

$T$ represents the overall differences in carbon emissions, $\mathrm{T}_{\mathrm{br}}$ represents the intra-regional differences in carbon emissions, and $\mathrm{T}_{\mathrm{br}}$ represents the regional differences in carbon emissions.

The three indices changed to some extent during the observation period (Table 5). Hence, the fluctuation of regional differences was relatively smooth. The changes of the Theil index were caused by intra-regional differences, which were greater than regional differences. It was found that there were some rules for the increases in regional differences of agricultural carbon emissions in the eight economic zones, which can be explained by the intra-regional differences.

Table 5. The Theil index of overall differences in carbon emissions for eight economic zones from 2000 to 2016.

\begin{tabular}{cccc}
\hline Year & $\mathbf{T}$ & $\mathbf{T}_{\mathbf{w r}}$ & $\mathbf{T}_{\mathbf{b r}}$ \\
\hline 2000 & 0.183697 & 0.032687 & 0.15101 \\
2001 & 0.17023 & 0.033136 & 0.137094 \\
2002 & 0.165671 & 0.03375 & 0.131921 \\
2003 & 0.142536 & 0.030557 & 0.11198 \\
2004 & 0.162128 & 0.026844 & 0.135284 \\
2005 & 0.13773 & 0.029721 & 0.108009 \\
2006 & 0.150411 & 0.030044 & 0.120367 \\
2007 & 0.166107 & 0.028339 & 0.137768 \\
2008 & 0.166595 & 0.030405 & 0.13619 \\
2009 & 0.157415 & 0.029726 & 0.127689 \\
2010 & 0.180821 & 0.027688 & 0.153133 \\
2011 & 0.169907 & 0.027065 & 0.142842 \\
2012 & 0.152046 & 0.026737 & 0.125308 \\
2013 & 0.143051 & 0.028387 & 0.114664 \\
2014 & 0.148396 & 0.028925 & 0.11947 \\
2015 & 0.158239 & 0.028747 & 0.129491 \\
2016 & 0.131406 & 0.026426 & 0.10498 \\
\hline
\end{tabular}

Data Source: calculated by the authors.

\subsection{The Theil Index in Eight Economic Zones}

Figure 5 shows the Theil index of overall differences of agricultural carbon emissions in eight economic zones from 2000 to 2016. It can be seen that the Theil index in the middle reaches of the Yangtze River was relatively stable, while that in the south coastal economic zone increased gradually, indicating that the overall differences in agricultural carbon emissions increased. Moreover, the Theil 
index in the southwest region and the south coast also increased, while those in the other economic zones had few changes for many years.

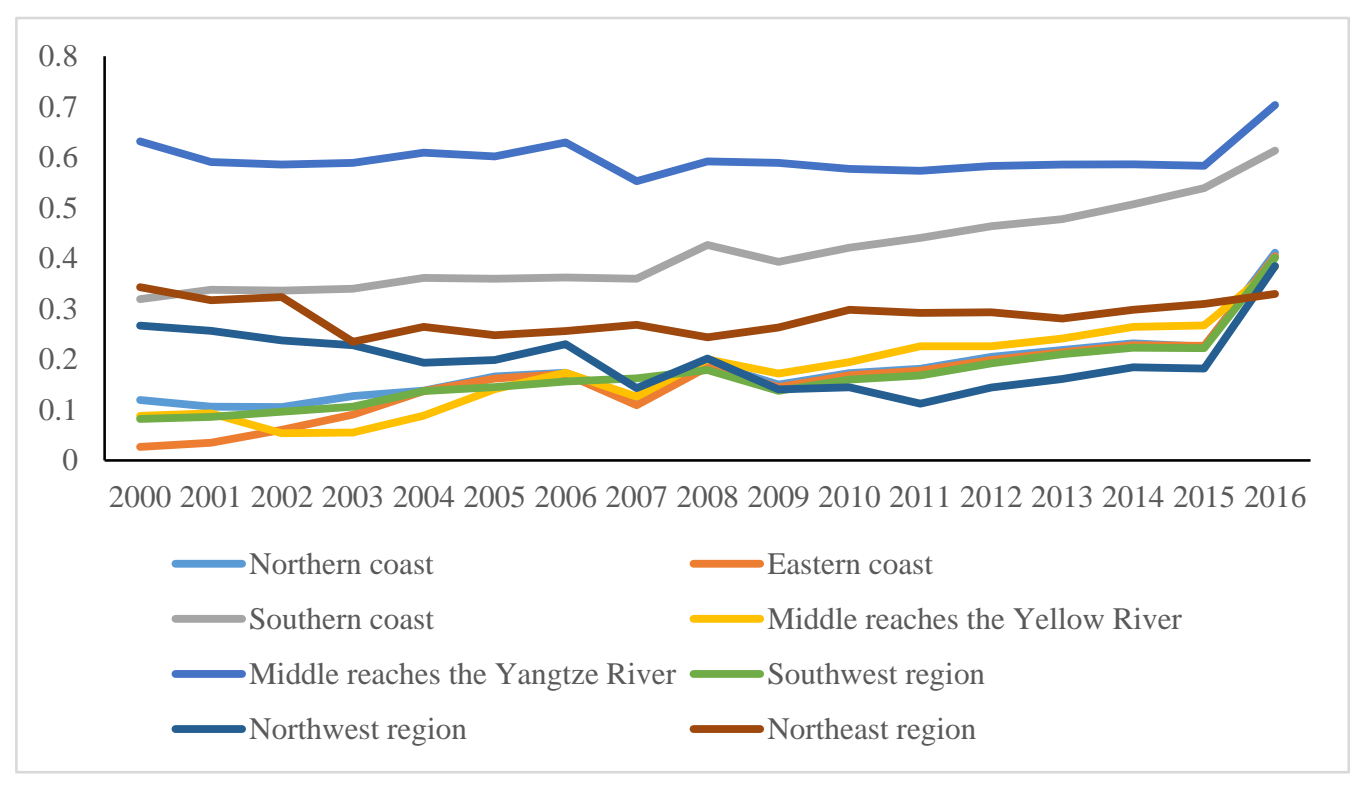

Figure 5. The Theil index of agricultural carbon emissions in eight economic zones.

The intra-regional differences of agricultural carbon emissions from 2000-2016 are summarized as follows:

The intra-regional differences of agricultural carbon emissions in the northern coastal region were relatively stable, with slight fluctuations in 2006 and 2009. It was generally stable, especially from 2009 to 2015, and then increased from 2016. The intra-regional differences of agricultural carbon emissions in the eastern coastal region declined gradually, and became the lowest among the eight economic zones from 2009. The trend of intra-regional differences of agricultural carbon emissions in the southern coastal region was consistent with that of the eastern coastal region, but with a lower speed. The peak of the intra-regional difference of agricultural carbon emissions in the middle reaches of the Yellow River appeared in 2008. The differences declined in 2019 and showed an upward trend from 2009 to 2016. The intra-regional differences of agricultural carbon emissions in the middle reaches of the Yangtze River were always the largest, and there was a sight fluctuation from 2006-2007. The intra-regional differences of agricultural carbon emissions in the southwest region increased from 2000 to 2005 and from 2008 to 2016, while they declined from 2005 to 2007. The intra-regional differences of agricultural carbon emissions in the northwest region and the northeast region from 2000 to 2016 were relatively stable.

Figure 6 shows radar charts of the changes of agricultural carbon emissions per capita in the eight economic zones in different years, measured by the variation coefficient method.

Generally, the agricultural carbon emissions per capita in the eight economic zones all showed an uptrend from 2000 to 2016. According to the circle layers of the radar charts, the regions in outer layers have higher agricultural carbon emissions per capita. It can be seen from Figure 6 that in 2000 and 2015 the agricultural carbon emissions per capita in the northeast economic zone and the northwest economic zone were the highest, while in 2010 and 2016, the agricultural carbon emissions per capita in the northeast economic zone were the highest.

The coefficients of variation increased from 2000 to 2005 and declined significantly from 2006 (Figure 7). Regional differences in carbon emissions per capita increased from 2007 to 2014, and declined from 2015. 

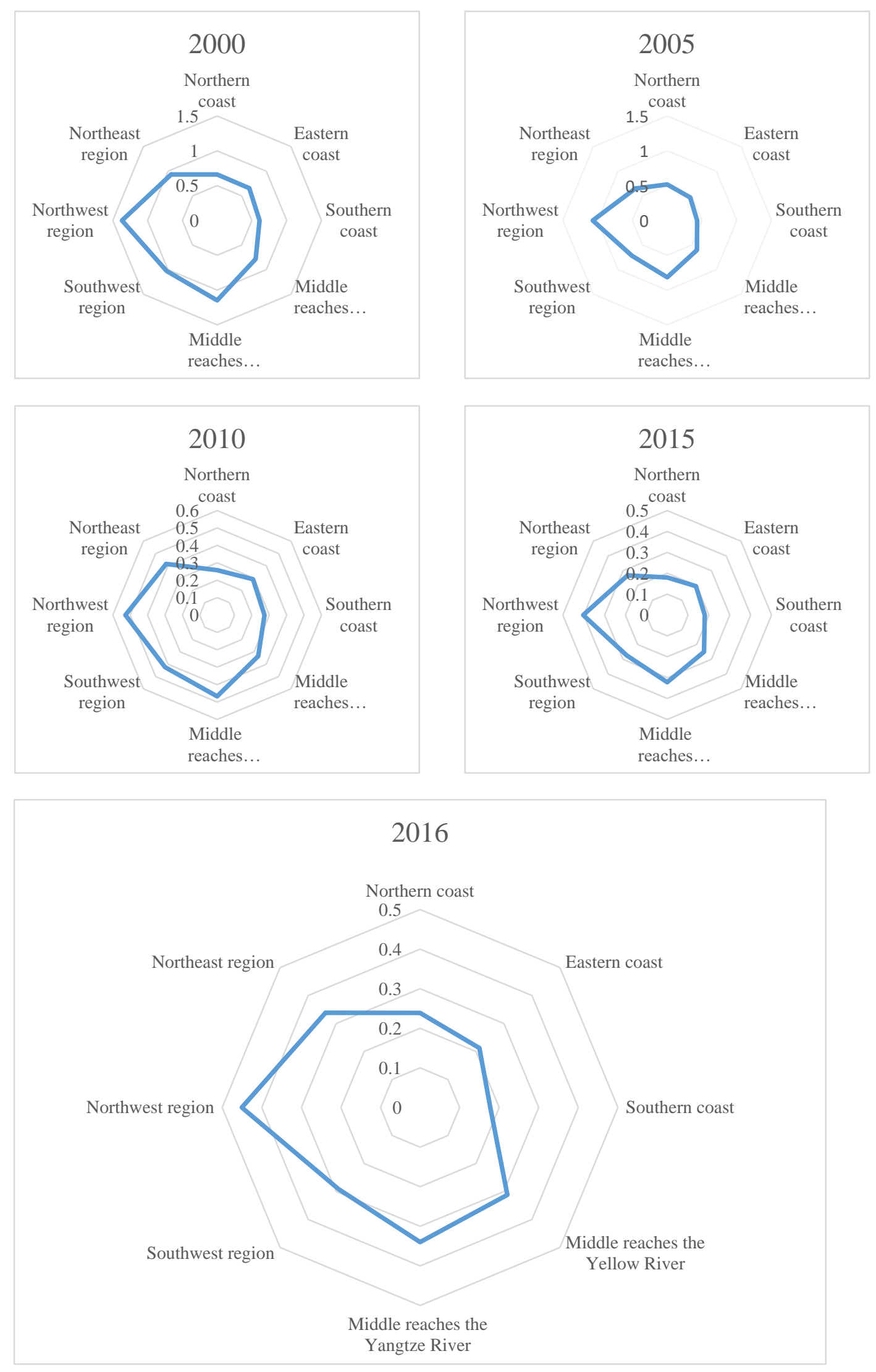

Figure 6. The intensities of agricultural carbon emissions per capita in eight economic zones. 


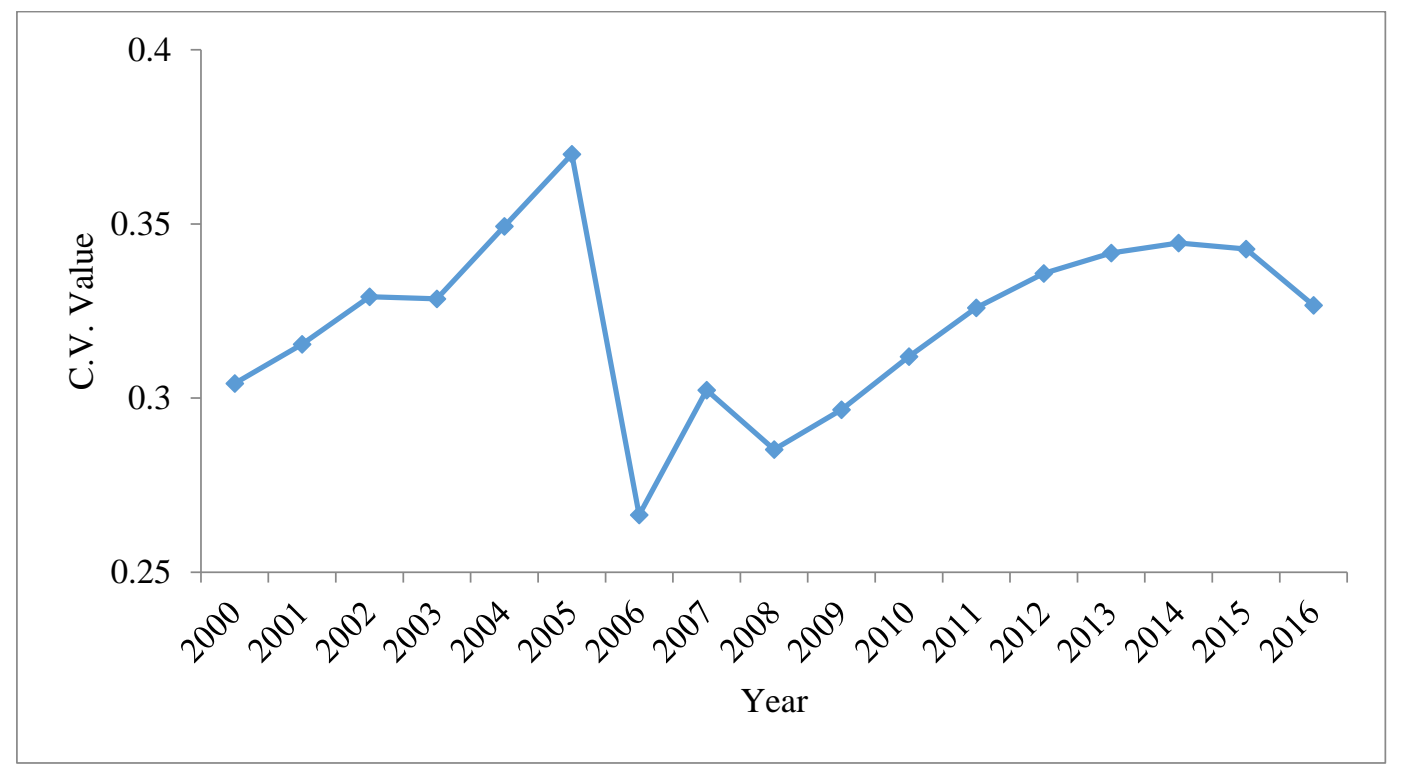

Figure 7. Coefficients of variation of agricultural carbon emissions in eight economic zones.

\section{Policy Recommendations for the Reduction of Regional Agricultural Carbon Emissions}

Based on the above research, this paper has constructed a matrix of total carbon emissions and the intensity of carbon emissions to analyze the regional policies for the reduction of agricultural carbon emissions in eight economic zones. The design of regional policy is a comprehensive and complex science, which needs classified considerations to ensure the pertinence of policy implementation.

The classified policy for the reduction of carbon emissions are important parts of China's national carbon emissions reduction policy. The classification of the intensity of carbon emissions and total agricultural carbon emissions are shown in Table 6.

Table 6. Classification of the intensity of carbon emissions and total agricultural carbon emissions.

\begin{tabular}{ccc}
\hline Regional Division & $\begin{array}{c}\text { Total Amount of Agricultural Carbon Emissions } \\
\mathbf{( 1 0 , 0 0 0 ~ t o n s )}\end{array}$ & $\begin{array}{c}\text { Intensity of Carbon Emissions } \\
\text { (ton/10,000 yuan) }\end{array}$ \\
\hline Low & $0-2000$ & $0-0.4$ \\
Medium & $2000-4000$ & $0.4-0.8$ \\
High & $>6000$ & $>0.8$ \\
\hline
\end{tabular}

Therefore, there are nine types of combinations of emission and intensity, including low emission and low intensity (LE\&LI), low emission and medium intensity (LE\&MI), low emission and high intensity (LE\&HI), medium emission and low intensity (ME\&LI), medium emission and medium intensity (ME\&MI), medium emission and high intensity (ME\&HI); high emission and low intensity (HE\&LI), high emission and medium intensity (HE\&MI), high emission and high intensity (HE\&HI). Agricultural production and livestock products are good outputs, while agricultural carbon emissions are bad outputs. The lower the intensity of agricultural carbon emissions is, the lower the carbon emissions of agricultural production per unit are. Therefore, low emission and low intensity (LE\&LI) tends to be the best combination (Table 7).

Based on the concept of coordinated development in the eight economic zones, this paper proposes that corresponding policies for the reduction of agricultural carbon emissions should be adopted for different economic zones. 
Table 7. Carbon emissions in eight economic zones.

\begin{tabular}{|c|c|c|c|c|c|c|c|c|}
\hline Year & $\begin{array}{l}\text { Northern } \\
\text { Coast }\end{array}$ & $\begin{array}{c}\text { Eastern } \\
\text { Coast }\end{array}$ & $\begin{array}{l}\text { Southern } \\
\text { Coast }\end{array}$ & $\begin{array}{c}\text { Middle } \\
\text { Reaches the } \\
\text { Yellow River }\end{array}$ & $\begin{array}{c}\text { Middle } \\
\text { Reaches the } \\
\text { Yangtze River }\end{array}$ & $\begin{array}{l}\text { Southwest } \\
\text { Region }\end{array}$ & $\begin{array}{l}\text { Northwest } \\
\text { Region }\end{array}$ & $\begin{array}{l}\text { Northeast } \\
\text { Region }\end{array}$ \\
\hline 2000 & ME \& MI & ME \& MI & ME \& MI & LE \& MI & HE \& HI & ME \& HI & LE \& HI & ME \& HI \\
\hline 2001 & ME\&MI & ME \& MI & LE \& MI & LE \& MI & HE \& HI & ME \& HI & LE \& HI & ME \& HI \\
\hline 2002 & ME\&MI & ME \& MI & LE \& MI & LE \& MI & HE \& HI & HE \& HI & LE \& HI & ME \& HI \\
\hline 2003 & ME\&MI & ME \& MI & LE \& MI & LE \& MI & HE \& HI & HE \& HI & LE \& HI & ME \& MI \\
\hline 2004 & ME\&MI & ME \& MI & LE \& MI & LE \& MI & HE \& HI & HE \& MI & LE \& HI & ME \& MI \\
\hline 2005 & ME\&MI & ME \& MI & LE \& MI & LE \& MI & HE \& HI & HE \& MI & LE \& HI & ME \& MI \\
\hline 2006 & ME\&MI & ME \& MI & LE \& MI & LE \& MI & HE \& HI & HE \& MI & LE \& HI & ME \& MI \\
\hline 2007 & ME\&LI & ME\&LI & LE \& LI & LE \& LI & HE \& MI & HE \& MI & LE \& HI & ME \& MI \\
\hline 2008 & ME\&LI & ME\&LI & LE \& LI & LE \& LI & HE \& MI & HE \& MI & ME \& HI & ME \& MI \\
\hline 2009 & ME\&LI & ME\&LI & LE \& LI & LE \& LI & HE \& MI & HE \& MI & ME \& MI & ME \& MI \\
\hline 2010 & ME\&LI & ME\&LI & LE \& LI & LE \& LI & HE \& MI & $\mathrm{HE} \& \mathrm{MI}$ & LE \& MI & ME \& MI \\
\hline 2011 & ME\&LI & ME\&LI & LE \& LI & LE \& LI & HE \& MI & HE \& LI & LE \& MI & ME \& LI \\
\hline 2012 & ME\&LI & ME\&LI & LE \& LI & LE \& LI & HE \& LI & HE \& LI & ME \& MI & ME \& LI \\
\hline 2013 & ME\&LI & ME\&LI & LE \& LI & LE \& LI & HE \& LI & HE \& LI & ME \& MI & ME \& LI \\
\hline 2014 & ME\&LI & ME\&LI & LE \& LI & LE \& LI & HE \& LI & HE \& LI & ME \& MI & ME \& LI \\
\hline 2015 & ME\&LI & ME\&LI & LE \& LI & LE \& LI & HE \& LI & HE \& LI & ME \& MI & ME \& LI \\
\hline 2016 & ME\&LI & ME\&LI & LE \& LI & LE \& MI & HE \& LI & HE \& LI & ME \& MI & HE \& LI \\
\hline
\end{tabular}

Note: Red-Yellow-Green, the agricultural carbon emissions and the intensity of agricultural carbon emissions decline gradually. —_HE\&HI; _-ME\&HI, HE\&MI; _-HE\&LI, LE\&HI; _-ME\&MI; —_ME\&LI;
LE\&MI; _LE\&LI

\subsection{Agricultural Development in the Northern Coastal Economic Zone}

The northern coastal economic zone includes the two cities of Beijing and Tianjin and the two provinces of Hebei and Shandong. The two provinces are important bases of agricultural production in China, especially Shandong province, which is also an important base of vegetable production in China. Moreover, Shandong also plays an important role in the development of modern agriculture. This region is generally characterized by a high level of openness and well-developed science and technology and transportation conditions. However, the integration process in this region is relatively slow as its agricultural products mainly support the Beijing area, which has hindered the establishment of a cooperation mechanism of carbon emission reduction among different provinces.

The agricultural carbon emissions in the northern coastal economic zone should be reduced and its intensity of agricultural carbon emissions should be controlled. Since leisure agriculture and picking agriculture in the suburbs of Beijing have been developed, Hebei and Shandong provinces can learn from its management technologies and methods to promote agricultural transformation. Furthermore, Shandong Province, as the largest exporter of agricultural products in China, should focus on the transformation of high-end and high value-added industries so as to realize the transformation and upgrading of industrial structure.

\subsection{Agricultural Development in the Eastern Coastal Economic Zone}

The development of the eastern coastal economic zone, which includes the city of Shanghai and the two provinces of Jiangsu and Zhejiang, has been promoted by China's reform and opening-up policy, and it has already become the center of China's modern industries. With 40 years of reform and opening up, the modern financial system in this region has been formed, and its agricultural input and output are already relatively high.

Therefore, the agricultural carbon emissions in this region should be reduced moderately. The high-end manufacturing industry can be a strong driving force for the development of agriculture in this region, which can also be accelerated by increasing the proportion of the tertiary industry; strengthening the development of logistics, consulting, and other industries as well as increasing brand awareness within the region. 


\subsection{Agricultural Development in the Southern Coastal Economic Zone}

The southern coastal economic zone covers the city of Guangzhou and the two provinces of Fujian and Hainan. With a high level of opening up due to its location near to Hong Kong (HK), Macau, and Taiwan, advanced foreign technologies are usually adopted firstly in this region, and it is also the main production base of consumer durable goods (such as cotton cloth). The main disadvantages in this region are the environmental pollution and the relatively high cost of pollution treatment.

The total amount and intensity of carbon emissions in this region should be maintained at the current level. As the center of foreign trade in China, the transformation and upgrade of the traditional processing industry can be promoted by making full use of the regional capital market-importing foreign capital, introducing advanced experience, improving the existing industrial development system, and enhancing the role of the value added by the regional wholesale market.

\subsection{Agricultural Development in the Middle Reaches of the Yellow River Economic Zone}

The middle reaches of the Yellow River economic zone includes the autonomous region of Inner Mongolia and the provinces of Shanxi, Shaanxi, and Henan, which are all important inland provinces in China. The pattern and level of economic development in this region are significantly different from those in the three economic zones mentioned above. The natural resources in this region are relatively rich, but the ecological environment has been greatly affected by long-term extensive cultivation. With a low agricultural output and insufficient level of opening up in this region, this region has faced great pressure to upgrade the industrial structure.

Therefore, active measures should be taken to reduce the total amount and intensity of carbon emissions in this region. With the improvement of production efficiency and the introduction of advanced technologies, the agricultural industry chain can be extended at the same time by enhancing regional and intra-regional cooperation, making full use of agricultural raw materials, such as edible fungi, and establishing a national logistics transportation network.

\subsection{Agricultural Development in the Middle Reaches of the Yangtze River Economic Zone}

The middle reaches of the Yangtze River economic zone includes the provinces of Hubei, Hunan, Jiangxi, and Anhui. With sufficient water sources and a large population, this region has developed a relatively mature agricultural system. However, its degree of opening up needs to be further improved, and its agricultural industrial structure should be upgraded.

For this region, moderate measures should be taken to reduce the total amount and intensity of agricultural carbon emissions. As the agricultural carbon emissions in this region are the highest in China, the proportion of high-tech industries can be increased by introducing the concept of large-scale agriculture, with emphasis on the development of leisure agriculture, agricultural tourism, and the transformation of agricultural products, so as to fully develop the modern agriculture in this region.

\subsection{Agricultural Development in the Southwest Economic Zone}

The southwest economic zone includes the city of Chongqing; the provinces of Yunnan, Guizhou, Sichuan, and others; and the autonomous region of Guangxi. Restricted by geographical factors, the scale of agriculture in this region tends to be small, and the quality of soil is relatively poor. However, the forestry in this region has been well developed, which provides a good foundation for the development of tourism.

Therefore, the agricultural carbon emissions should be reduced moderately and the intensity of carbon emissions should be controlled. The degree of agricultural modernization in this region can be improved by enhancing the management of agricultural production and introducing modern agricultural industry systems, such as a picking industry. 


\subsection{Agricultural Development in the Northwest Economic Zone}

The northwest economic zone includes the provinces of Gansu and Qinghai, and the autonomous regions of Ningxia, Tibet, and Xinjiang. This region is not only the largest base of deep processing for cotton, grain, and oil products but also an important energy base in China. The production of the primary industry accounts for a large proportion of the gross production in this region, and the conditions for agricultural development are relatively poor.

Therefore, the total amount and intensity of agricultural carbon emissions in this region should be maintained at the current level. Due to the strong light throughout the year, the proportion of fruit products in the agricultural market can be gradually increased with the overall agricultural carbon emissions unchanged, and industrial upgrading can be promoted by cotton production.

\subsection{Agricultural Development in Northeast Economic Zone}

The northeast economic zone, which includes Liaoning, Jilin, and Heilongiiang provinces, is characterized by good agricultural production conditions. In recent years, this region has faced the pressure of depleting resources and industrial structure upgrading.

The total agricultural carbon emissions in this region should be reduced moderately and the intensity should be controlled. Furthermore, with the experiences of resource transformation at home and abroad, taking the opportunity of establishing a national carbon emission market and the rich carbon storage in this region, the management and maintenance of agricultural land can be enhanced and the area of forestry can be increased.

\section{Conclusions and Discussion}

This paper measured the agricultural carbon emissions in China, and compared the regional differences of agricultural carbon emissions using the method of coefficient of variation and the Theil index by taking four regions and eight economic zones as research areas. The results showed that, in 2016, China's total carbon emissions were 272.022 million tons, which is $26.67 \%$ more than that in 2000 , and the average annual increase was $1.67 \%$. Among them, carbon emissions caused by agricultural land use, rice cultivation, and livestock and poultry were 110.5649 million tons, 70.193 million tons, and 91.2642 million tons, respectively, accounting for $40.64 \%, 25.8 \%$, and $33.55 \%$ of agricultural carbon emissions. The total agricultural carbon emissions of the three aspects mentioned above all increased from 2000 to 2016. To be specific, carbon emissions from agricultural land use increased the fastest, from 73.9473 million tons to 110.5649 million tons, with an average annual increase of $3.09 \%$. That means the increase of agricultural output in China depends greatly on the increase of agricultural material input. There were great fluctuations in the carbon emissions from rice cultivation, which increased slightly from 69.7028 million tons in 2000 to 70.193 million tons in 2016, with an average annual increase of $0.04 \%$. Carbon emissions from rice cultivation are mainly affected by the scale and structure of rice cultivation. Carbon emissions from livestock and poultry farming increased from 71.1037 million tons in 2000 to 91.2642 million tons in 2016, with an average annual increase of $1.77 \%$. Affected by the scale and structure of livestock and poultry farming, the change of carbon emissions from livestock and poultry farming can be divided into five periods: a period of continuous rising (2000 -2005), a period of rapid declining (2006-2007), a period of rapid rising (2007-2008), a period of declining (2008-2009), and a period of steady growth (2009-2016). Agricultural carbon emissions per capita in eight economic zones all showed an uptrend from 2000 to 2016. In addition, in 2000 and 2015, the agricultural carbon emissions per capita in the northeast economic zone and the northwest economic zone were the highest, while in 2010 and 2016, only the agricultural carbon emissions per capita in the northeast economic zone were the highest. Based on the concept of coordinated development in the eight economic zones and their important positions in China's agricultural development, this paper proposes some policy recommendations for the reduction of agricultural carbon emissions. Compared with Tian's (2012) conclusions [32], in China, the intensity of agricultural carbon emissions declined from the west to the 
east (Figure 3), and in 2016, the intensity of agricultural carbon emissions showed a trend of northwest region $>$ middle reaches the Yangtze River $>$ northeast region $>$ southwest region $>$ northern Coast $>$ eastern coast $>$ southern coast, which is of strong similarity to previous literature.

Agricultural carbon emissions caused by straw burning and $\mathrm{N}_{2} \mathrm{O}$ were not taken into consideration in this paper, as existing researches have shown different results for carbon emissions caused by $\mathrm{N}_{2} \mathrm{O}$. The regional differences of agricultural carbon emissions in this paper were only estimated on the basis of total carbon emissions and the intensity of carbon emissions. However, the efficiency of carbon emissions is also a very important indicator, which should be considered in further research.

Author Contributions: Conceptualization, J.J.; Methodology, G.W.; Software, G.W.; Validation, G.W., M.L. and J.J.; Formal Analysis, G.W.; Investigation, G.W.; Data Curation, G.W.; Writing-Original Draft Preparation, G.W.; Writing-Review \& Editing, M.L.; Visualization, M.L.; Supervision, M.L. All authors have read and agreed to the published version of the manuscript.

Funding: This research was financially supported by the Key Research and Development Program of the Ministry of Science and Technology, China grant number [NO. 71602006]; and the Youth Fund Project of the Humanities and Social Science Program of Ministry of Education, China [NO. 18YJC630174].

Conflicts of Interest: The authors declare no conflict of interest.

\section{References}

1. Bai, Y.; Deng, X.; Gibson, J.; Zhao, Z.; Xu, H. How does urbanization affect residential $\mathrm{CO}_{2}$ emissions? An analysis on urban agglomerations of China. J. Clean. Prod. 2019, 209, 876-885. [CrossRef]

2. First, P.J. Global Warming of 1.5 C An IPCC Special Report on the Impacts of Global Warming of 1.5 C Above Pre-Industrial Levels and Related Global Greenhouse Gas Emission Pathways, in the Context of Strengthening the Global Response to the Threat of Climate Change. Sustainable Development, and Efforts to Eradicate Poverty. Available online: https://www.ipcc.ch/sr15/ (accessed on 1 January 2019).

3. Bongaarts, J. Intergovernmental Panel on Climate Change Special Report on Global Warming of $1.5^{\circ} \mathrm{C}$ Switzerland: IPCC, 2018. Popul. Dev. Rev. 2018, 45, 251-252. [CrossRef]

4. Asadnabizadeh, M. Development of UN Framework Convention on Climate Change Negotiations under COP25: Article 6 of the Paris Agreement perspective. Open Political Sci. 2019, 2, 113-119. [CrossRef]

5. Intergovernmental Panel on Climate Change. Special Report on Climate Change and Land. In Proceedings of the Intergovernmental Panel on Climate Change (IPCC), Geneva, Switzerland, 2-6 August 2019; IPCC: Georgia Batumi, Switzerland.

6. Zhao, R.Q.; Huang, X.J.; Zhong, T.Y. Research on carbon emission intensity and carbon footprint of different industrial spaces in China. Acta Geogr. Sin. 2010, 65, 1048-1057.

7. Lu, H.; Xie, H.; Lv, T.; Yao, G. Determinants of cultivated land recuperation in ecologically damaged areas in China. Land Use Policy 2019, 81, 160-166. [CrossRef]

8. Davis, K.F.; Yu, K.; Rulli, M.C.; Pichdara, L.; D'Odorico, P. Accelerated deforestation driven by large-scale land acquisitions in Cambodia. Nat. Geosci. 2015, 8, 772-775. [CrossRef]

9. Pimentel, D.; Burgess, M. Soil Erosion Threatens Food Production. Agriculture 2013, 3, 443-463. [CrossRef]

10. Environment and Climate Change Canada. Achieving a Sustainable Future: 2016-2019 A Federal Sustainable Development Strategy for Canada; Environment and Climate Change Canada, 2016. Available online: http://www.fsds-sfdd.ca/index.html\#/en/goals/ (accessed on 1 January 2019).

11. He, Y.; Chen, R.; Wu, H.; Xu, J.; Song, Y. Spatial dynamics of agricultural carbon emissions in China and the related driving factors. Chin. J. Eco-Agric. 2018, 26, 1269-1282. [CrossRef]

12. Dong, G.; Mao, X.; Zhou, J.; Zeng, A. Carbon footprint accounting and dynamics and the driving forces of agricultural production in Zhejiang Province, China. Ecol. Econ. 2013, 91, 38-47. [CrossRef]

13. Altieri, M.A.; Nicholls, C.I. The adaptation and mitigation potential of traditional agriculture in a changing climate. Clim. Chang. 2013, 140, 33-45. [CrossRef]

14. Liu, J.; Diamond, J. China's environment in a globalizing world. Nature 2005, 435, 1179-1186. [CrossRef]

15. Xiong, C.; Chen, S.; Yang, D. Selecting Counties to Participate in Agricultural Carbon Compensation in China. Pol. J. Environ. Stud. 2019, 28, 1443-1449. [CrossRef]

16. Lal, R. Carbon Management in Agricultural Soils. Mitig. Adapt. Strat. Glob. Chang. 2006, 12, $303-322$. [CrossRef] 
17. Gao, M.; Song, H. Dynamic Changes and Spatial Agglomeration Analysis of the Chinese Agricultural Carbon Emissions Performance. Econ. Geogr. 2015, 35, 142-148.

18. Cong, J.; Liu, X.; Zhao, X. Demarcation Problems and the Corresponding Measurement Methods of the Urban Carbon Accounting. China Popul. Resour. Environ. 2014, 4, 19-26.

19. You, H.; Wu, C. Analysis of carbon emission efficiency and optimization of low carbon for agricultural land intensive use. Trans. Chin. Soc. Agric. Eng. 2014, 30, 224-234. [CrossRef]

20. Goldstein, B.; Hauschild, M.Z.; Fernandez, J.; Birkved, M. Testing the environmental performance of urban agriculture as a food supply in northern climates. J. Clean. Prod. 2016, 135, 984-994. [CrossRef]

21. Nurse, J.; Basher, D.; Bone, A.; Bird, W. An ecological approach to promoting population mental health and well-being-A response to the challenge of climate change. Perspect. Public Health 2010, 130, 27-33. [CrossRef]

22. Zou, Y.; Wei, N.; Chen, F.; Tang, Q.; Wang, L. The regional differences of carbon emission in China. In Proceedings of the World Automation Congress 2012, Puerto Vallarta, Mexico, 24-28 June 2012.

23. Venterea, R.T.; Halvorson, A.D.; Kitchen, N.; Liebig, M.; Cavigelli, M.A.; Del Grosso, S.J.; Motavalli, P.P.; Nelson, K.A.; Spokas, K.A.; Singh, B.; et al. Challenges and opportunities for mitigating nitrous oxide emissions from fertilized cropping systems. Front. Ecol. Environ. 2012, 10, 562-570. [CrossRef]

24. Hiraishi, T.; Krug, T.; Tanabe, K.; Srivastava, N.; Baasansuren, J.; Fukuda, M.; Troxler, T.G. 2013 Supplement to the 2006 IPCC Guidelines for National Greenhouse Gas Inventories: Wetlands; IPCC: Georgia Batumi, Switzerland, 2014.

25. Nezahat, D. Agriculture and Environmental Kuznets Curves in the case of Turkey: Evidence from the ARDL and bounds test. Agric. Econ. 2016, 62, 566-574. [CrossRef]

26. Zhang, G.; Wang, S. China's Agricultural Carbon Emission: Structure, Efficiency and Its Determinants. Agric. Econ. 2014, 7, 18-26.

27. Huang, W.; Hu, Y.; Ren, Y.; Cui, S.; Gao, B. Carbon emission of agricultural production associated with urban food consumption: Ningbo as a case study. Acta Sci. Circumst. 2015, 35, 4102-4111. [CrossRef]

28. Yan, T.; Tian, Y.; Zhang, J.; Wang, Y. Research on Inflection Point Change and Spatial and Temporal Variation of China's Agricultural Carbon Emissions. China Popul. Resour. Environ. 2014, 1-8. [CrossRef]

29. Deng, J.; Liu, X.; Wang, Z. Characteristics Analysis and Factor Decomposition Based on the Regional Difference Changes in China's $\mathrm{CO}_{2}$ Emission. J. Nat. Resour. 2014, 29, 189-200.

30. Pang, L. Empirical study of regional carbon emissions of agriculture in China. J. Arid Land Resour. Environ. 2014, 28, 1-7.

31. Tian, Y.; Zhang, J.B.; He, Y.Y. Research on Spatial-Temporal Characteristics and Driving Factor of Agricultural Carbon Emissions in China. J. Integr. Agric. 2014, 6, 243-253. [CrossRef]

32. Tian, Y.; Zhang, J.B.; Li, B. Agricultural carbon emissions in China: Calculation, spatial-temporal comparison and decoupling effects. Resour. Sci. 2012, 34, 2097-2105.

33. Dai, X.; He, Y.; Zhong, Q. Driving factors and their contributions to agricultural $\mathrm{CO}_{2}$ emission due to energy consumption in China: Based on an expended Kaya identity and LMDI decomposition method. Chin. J. Eco-Agric. 2015, 23, 1445-1454.

34. Tian, Y.; Zhang, J.; Chen, Q. Distributional dynamic and trend evolution of China's agricultural carbon emissions-An analysis on panel data of 31 provinces from 2002 to 2011. Chin. J. Popul. Resour. Environ. 2015, 13, 206-214. [CrossRef]

35. Sun, Y.; Li, H.; Wang, C. Empirical Study of Functional Mechanism of China's Trade Openness on Carbon Emissions. J. Int. Trade 2015, 2, 63-71.

36. Shu-Jie, Y.; Yu-Bo, L.; Shou-Gang, Y. An Empirical Analysis of the Decoupling Relationship between Agricultural Carbon Emission and Economic Growth in Jilin Province. IOP Conf. Ser. Mater. Sci. Eng. 2018, 392, 062101. [CrossRef]

37. Sun, Q. Ecological agriculture development and spatial and temporal characteristics of carbon emissions of land use. Appl. Ecol. Environ. Res. 2019, 17, 11045-11053. [CrossRef]

38. Liu, X.; Yu, Y.; Luan, S. Empirical Study on the Decomposition of Carbon Emission Factors in Agricultural Energy Consumption. IOP Conf. Ser. Earth Environ. Sci. 2019, 252, 042045. [CrossRef]

39. Chen, Y.; Li, M.; Su, K.; Li, X. Spatial-Temporal Characteristics of the Driving Factors of Agricultural Carbon Emissions: Empirical Evidence from Fujian, China. Energies 2019, 12, 3102. [CrossRef] 
40. Zhang, L.; Pang, J.; Chen, X.; Lu, Z. Carbon emissions, energy consumption and economic growth: Evidence from the agricultural sector of China's main grain-producing areas. Sci. Total Environ. 2019, 665, 1017-1025. [CrossRef]

41. Huang, X.; Xu, X.; Wang, Q.; Zhang, L.; Gao, X.; Chen, L. Assessment of Agricultural Carbon Emissions and Their Spatiotemporal Changes in China, 1997-2016. Int. J. Environ. Res. Public Health 2019, 16, 3105. [CrossRef]

42. Chen, X.; Shuai, C.; Wu, Y.; Zhang, Y. Analysis on the carbon emission peaks of China's industrial, building, transport, and agricultural sectors. Sci. Total Environ. 2020, 709, 135768. [CrossRef]

43. Akiyama, H.; Yan, X.; Yagi, K. Evaluation of effectiveness of enhanced-efficiency fertilizers as mitigation options for $\mathrm{N} 2 \mathrm{O}$ and $\mathrm{NO}$ emissions from agricultural soils: Meta-analysis. Glob. Chang. Biol. 2010, 16, 1837-1846. [CrossRef]

44. Balsalobre-Lorente, D.; Driha, O.M.; Bekun, F.V.; Osundina, O. Do agricultural activities induce carbon emissions? The BRICS experience. Environ. Sci. Pollut. Res. 2019, 26, 25218-25234. [CrossRef]

45. Frank, S.; Havlik, P.; Stehfest, E.; Van Meijl, H.; Witzke, P.; Pérez-Domínguez, I.; Van Dijk, M.; Doelman, J.C.; Fellmann, T.; Koopman, J.F.L.; et al. Agricultural non- $\mathrm{CO}_{2}$ emission reduction potential in the context of the $1.5^{\circ} \mathrm{C}$ target. Nat. Clim. Chang. 2018, 9, 66-72. [CrossRef]

46. Wang, J.; Rothausen, S.G.S.A.; Conway, D.; Zhang, L.; Xiong, W.; Holman, I.P.; Li, Y. China's water-energy nexus: Greenhouse-gas emissions from groundwater use for agriculture. Environ. Res. Lett. 2012, 7, 014035. [CrossRef]

47. Dumortier, J.; Hayes, D.J.; Carriquiry, M.; Dong, F.; Du, X.; Elobeid, A.; Tokgoz, S.; Fabiosa, J.F. Sensitivity of carbon emission estimates from indirect land-use change. Appl. Econ. Perspect. Policy 2011, 33, 428-448. [CrossRef]

48. De Souza, J.P.; Bortolon, E.S.O.; Bortolon, L.; De Camargo, F.P.; Conceição, W.S.S.; Lima, A.D.O.; Vezzani, F.M. Carbon Dioxide Emissions in Agricultural Systems in the Brazilian Savanna. J. Agric. Sci. 2019, 11, 242. [CrossRef]

49. Wei, Q.; Qu, J.S.; Bai, J.; Li, H.J.; Liu, L.N.; Xu, L. Influencing factors of agricultural carbon emission and regional differences between south and north in China. J. Ecol. Rural Environ. 2018, 34, 318-325. [CrossRef]

(C) 2020 by the authors. Licensee MDPI, Basel, Switzerland. This article is an open access article distributed under the terms and conditions of the Creative Commons Attribution (CC BY) license (http://creativecommons.org/licenses/by/4.0/). 